\title{
Inactivation of the MAPK signaling pathway by Listeria monocytogenes infection promotes trophoblast giant cell death
}

\author{
Masanori Hashino', Masato Tachibana',2, Takashi Nishida', Hideki Hara ${ }^{3,4}$, \\ Kohsuke Tsuchiya ${ }^{3,5}$, Masao Mitsuyama $^{3,6}$, Kenta Watanabe ${ }^{1,7}$, Takashi Shimizu ${ }^{1,7}$ and \\ Masahisa Watarai ${ }^{1,7 *}$
}

\begin{abstract}
1 The United Graduate School of Veterinary Science, Yamaguchi University, Yoshida Campus, Yamaguchi, Japan, ${ }^{2}$ Division of Biomedical Food Research, National Institute of Health Sciences, Tokyo, Japan, ${ }^{3}$ Department of Microbiology, Graduate School of Medicine, Kyoto University, Kyoto, Japan, ${ }^{4}$ Department of Pathology and Comprehensive Cancer Center, University of Michigan Medical School, Ann Arbor, MI, USA, ${ }^{5}$ Division of Immunology and Molecular Biology, Cancer Research Institute, Kanazawa University, Kanazawa, Japan, ${ }^{6}$ Graduate School of Advanced Integrated Studies in Human Survivability, Kyoto University, Kyoto, Japan, ${ }^{7}$ Laboratory of Veterinary Public Health, Joint Faculty of Veterinary Medicine, Yamaguchi University at Yamaguchi, Yamaguchi, Japan
\end{abstract}

\section{OPEN ACCESS}

Edited by:

Mario T. Philipp,

Tulane National Primate Research

Center - Tulane University, USA

Reviewed by:

Laurel L. Lenz,

University of Colorado School

of Medicine, USA

Geetha Parthasarathy,

Tulane National Primate Research

Center, USA

*Correspondence:

Masahisa Watara

watarai@yamaguchi-u.ac.jp

Specialty section:

This article was submitted to

Microbial Immunology,

a section of the journal

Frontiers in Microbiology

Received: 10 July 2015 Accepted: 05 October 2015 Published: 16 October 2015

Citation: Hashino M, Tachibana M, Nishida T, Hara H, Tsuchiya K, Mitsuyama M, Watanabe K, Shimizu T and Watarai $M$ (2015) Inactivation of the MAPK signaling pathway by Listeria monocytogenes infection promotes trophoblast giant cell death.

Front. Microbiol. 6:1145. doi: 10.3389/fmicb.2015.01145
Listeria monocytogenes has a well-characterized ability to cross the placental barrier, resulting in spontaneous abortion and fetal infections. However, the mechanisms resulting in infection-associated abortion are not fully understood. In this study, we demonstrate that the dephosphorylation of MAPK family proteins caused by L. monocytogenes infection of trophoblast giant (TG) cells, which are placental immune cells, contributes to infectious abortion. Dephosphorylation of c-Jun, p38, and ERK1/2 was observed in infected TG cells, causing the downregulation of cytoprotective heme oxygenase (HO)-1. Blocking the dephosphorylation of proteins, including MAPK family proteins, inhibited the decrease in HO-1 expression. Treatment with MAPK inhibitors inhibited bacterial internalization into TG cells. Moreover, Toll-like receptor 2 involved in the expression of MAPK family proteins. Infection with a listeriolysin O-deleted mutant impaired dephosphorylation of MAPK family proteins in TG cells and did not induce infectious abortion in a mouse model. These results suggest that inactivation of the MAPK pathway by $L$. monocytogenes induces TG cell death and causes infectious abortion.

Keywords: Listeria monocytogenes, MAPK, infection, abortion, placenta, trophoblast

\section{INTRODUCTION}

Human listeriosis is a food-borne disease resulting from the ingestion of contaminated food, such as dairy products, vegetables, raw seafood, poultry, and processed meat (Hernandez-Milian and Payeras-Cifre, 2014). Listeria monocytogenes is the Gram-positive bacterium and causative agent of listeriosis. In humans, listeriosis causes gastroenteritis, maternofetal infections, and meningoencephalitis due to L. monocytogenes ability to cross the blood-brain, placental, and intestinal barriers. An important virulence feature of L. monocytogenes is its ability to escape from the killing mechanisms of phagocytic host cells, such as macrophages (Stavru et al., 2011a; Ribet and Cossart, 2015). 
Pregnancy causes a widely suppression of the adaptive immune system, characterized by a decreased cell-mediated immunity and the suppressed response of cytotoxic $\mathrm{T}$ cells (Gluhovschi et al., 2015). Maternal rejection of the fetus is prevented by the immunosuppressed state; however, it has the unexpected effect of increasing maternal susceptibility to abortion-inducing pathogens (Dhama et al., 2015). L. monocytogenes is an intracellular pathogen and its immunity is principally mediated by cellular immune responses (Parmer, 2004). In our previous study, the abortion was observed in pregnant mouse model infected with abortion-inducing bacteria, such as L. monocytogenes and Brucella abortus (Kim et al., 2005; Tachibana et al., 2008, 2011). In Brucella infection, compared to other organs, a large amount of bacterial colonization was found in the placenta, especially in the placental trophoblast giant (TG) cells. In contrast, an intracellular replication-defective mutant failed to induce abortion in a pregnant mouse model (Kim et al., 2005). In addition, infection of B. abortus induced a transient increase in interferon- $\gamma$ (IFN- $\gamma$ ) levels in pregnant mice. Furthermore, this transient IFN- $\gamma$ production leads to infectious abortion, and depletion of IFN- $\gamma$ by neutralization inhibits infectious abortion (Kim et al., 2005). These reports of $B$. abortus infection imply that bacterial internalization and intracellular replication in TG cells are both key aspects in abortion and that TG cells are closely associated with the evasion of maternal immune rejection.

Trophoblast giant cells are essential for the establishment of pregnancy. TG cells are polyploid cells differentiated from trophoblast stem (TS) cells. TG cells have diverse functions that are crucial for implantation and subsequent placental function such as vasculature remodeling and uterine immune system (Hu and Cross, 2010). They form the fetal component of the placenta (Parast et al., 2001). In particular, TG cells regulate maternal spiral artery remodeling and maternal blood flow into the placenta in mice (Hu and Cross, 2010). TG cells in the mouse placenta are analogous to extravillous cytotrophoblast (EVT) cells in the human placenta (Baczyk et al., 2004). L. monocytogenes and Toxoplasma gondii enter into EVT cells preferentially in primary human placental organ cultures (Robbins et al., 2010, 2012). Trophoblast cells show phagocytic feature. Trophoblast cells phagocytose stroma and uterine epithelial cells and invade maternal tissue during implantation (Welsh and Enders, 1987). Several of the mechanisms contributed to phagocytic ability of trophoblast cells have been published (Drake and Rodger, 1987), however, the detail process is still unclear. Another report showed that trophoblast cells have the ability of bacterial uptake and that IFN- $\gamma$ treatment enhaces this activity (Amarante-Paffaro et al., 2004). Therefore, trophoblast cells may have phagocytic activity against pathogenic agents in a same way of macrophages. These studies suggest that trophoblast cells play roles in the placental defense system as well as in the development and maintenance of placenta.

Various cell types, such as dendritic cells (Guzmán et al., 1996), lymphocytes (Merrick et al., 1997), and hepatocytes (Rogers et al., 1996), are induced cell death in vitro and in vivo by L. monocytogenes infection. The pore-forming toxin listeriolysin $\mathrm{O}$ (LLO) play important role in cell death induced by L. monocytogenes. LLO is the key factor responsible for degradation of the vacuole and escaping into the cytosol. In previous studies, we demonstrated that Listeria and Brucella infections are associated with the death of TG cells. We also found that reduction of heme oxygenase (HO)-1 expression by bacterial infection enhanced infectious abortions in vivo and cell death in vitro (Tachibana et al., 2008, 2011). HO1 plays key roles in cytoprotection, antioxidation, and antiinflammation. The majority of HO-1's physiological functions are associated with its enzymatic activity in heme catabolism (Hegazi et al., 2005; Nakahira et al., 2006). HO-1 deficiency causes an increased pro-inflammatory state and susceptibility to oxidative stress in humans (Yachie et al., 1999). HO-1 deficient mice acquire progressive chronic inflammatory disease (Poss and Tonegawa, 1997a) and express enhanced toxemia caused by lipopolysaccharide administration (Poss and Tonegawa, 1997b). Although the protective characteristics of HO-1 have been studied using various inflammatory models (Lee and Chau, 2002; Chora et al., 2007; Pamplona et al., 2007), the molecular mechanisms, timing, and mode of HO-1 function during disease remains largely unknown.

The mitogen-activated protein kinase (MAPK) signal transduction pathway is one of the most important regulatory mechanisms in eukaryotic cells and a central signaling cascade that is essential for the host immune response (Krachler et al., 2011). In mammals, there are at least four subfamilies of MAPKs, including the extracellular signal-regulated kinases (ERKs), the c-Jun $\mathrm{NH}_{2}$-terminal kinases (JNKs), the p38 isoforms (p38s), and ERK5 (Tanoue and Nishida, 2003; Turjanski et al., 2007). These kinases are organized as parallel cascades in which the activation of each component is regulated upstream and downstream by phosphorylation events (Chang and Karin, 2001). As in mouse TG cells, a large amount of phosphorylated MAPK family protein is detected in bovine TG cells. The localization of actin, its associated proteins, and phosphorylated MAPK family proteins, suggests their involvement in TG cell migration in bovine placentomes (Lang et al., 2004).

In the present study, we investigated the dephosphorylation of MAPK family proteins during L. monocytogenes infection in TG cells. Our results suggest that $L$. monocytogenes LLO contributes to the inhibition of MAPK signaling pathway activation and infection-associated abortion.

\section{MATERIALS AND METHODS}

\section{Bacterial Strains}

Listeria monocytogenes strains EGD, $\Delta h l y$, and $\Delta h l y:$ :hly (Hara et al., 2007) and Escherichia coli DH5 $\alpha$ were used in this study. Two isogenic mutants of L. monocytogenes, $\Delta$ hly and $\Delta h l y:: h l y$ were generated from parental strain using the method of homologous recombination and the expression level of LLO was shown in a previous study (Hara et al., 2007). L. monocytogenes strains, which were maintained in frozen glycerol stocks, were cultured overnight in brain heart infusion (BHI) broth (Becton Dickinson, Franklin Lakes, NJ, USA) at $37^{\circ} \mathrm{C}$ with shaking or on $\mathrm{BHI}$ broth containing $1.5 \%$ agar (Wako, Osaka, Japan) at $37^{\circ} \mathrm{C}$ 
under aerobic condition. E. coli $\mathrm{DH} 5 \alpha$ was cultured in LuriaBertani (LB) broth (MO BIO Laboratories, Inc., Carlsbad, CA, USA) or on LB broth containing $1.5 \%$ agar.

\section{Cell Culture}

A mouse TS cell line was gifted by Dr. Tanaka (Tanaka et al., 1998). Cell culture was done by using the same method described previously (Hashino et al., 2012). TS cells were cultured in a mixed medium (TS medium: mouse embryonic fibroblastconditioned medium $=3: 7$ ) supplemented with $25 \mathrm{ng} / \mathrm{ml}$ fibroblast growth factor 4 (TOYOBO, Osaka, Japan) and $1 \mu \mathrm{g} / \mathrm{ml}$ heparin (Sigma, St. Louis, MO, USA), as described in our previous study (Hashino et al., 2012). TS medium was prepared by adding $20 \%$ (v/v) fetal bovine serum (FBS), $1 \mathrm{mM}$ sodium pyruvate, $100 \mu \mathrm{M} \beta$-mercaptoethanol, and $2 \mathrm{mM}$ L-glutamine to RPMI 1640 medium. TS cells were cultured in TS medium alone for 3 days at $37^{\circ} \mathrm{C}$ in an atmosphere containing $5 \% \mathrm{CO}_{2}$ for inducing cell differentiation of TS cells to TG cells. TG cells were seeded in 48 -well $\left(1-2 \times 10^{5}\right.$ per well $)$ or 12 -well $\left(4-8 \times 10^{5}\right.$ per well) tissue culture plates. After differentiation into TG cells, the cells were incubated in RPMI 1640 medium for $24 \mathrm{~h}$ before use.

\section{Immunoblotting}

Immunoblotting was done by using the modified method described previously (Hashino et al., 2012). TG cells were washed twice with phosphate-buffered saline (PBS) and lysed in lysis buffer ice-cold PBS containing 1\% (v/v) Triton X-100, $1 \mathrm{mM}$ sodium orthovanadate (SOV), $2 \mathrm{mM}$ phenylmethylsulfonyl fluoride, $100 \mathrm{mM}$ sodium fluoride, and $1 \times$ Halt Protease Inhibitor Cocktail Kit (Thermo Fisher Science, Rockford, IL, USA) at $4^{\circ} \mathrm{C}$ for $30 \mathrm{~min}$, and sonicated three times for $10 \mathrm{~s}$ each. the supernatants of cell lysates were collected by centrifugation $\left(16,000 \times g, 4^{\circ} \mathrm{C}, 20 \mathrm{~min}\right.$; Hashino et al., 2012). Protein concentrations were measured using by the Bio-Rad Protein Assay (Bio-Rad, Richmond, CA, USA). After separating $300 \mathrm{ng}$ of each protein by SDS-PAGE using 12\% polyacrylamide gels, the proteins were electrically transferred onto polyvinylidene difluoride (PVDF) membranes (Millipore, Billerica, MA, USA). After membranes were blocked for $2 \mathrm{~h}$ with $5 \%(\mathrm{w} / \mathrm{v})$ non-fat dry milk in Tris-buffered saline (TBS) at room temperature, membranes were incubated with antimouse Phospho-c-Jun rabbit monoclonal antibody (1:1,000; Cell Signaling Technology, Danvers, MA, USA), anti-mouse c-Jun rabbit monoclonal antibody (1:1,000; Cell Signaling Technology), anti-mouse Phospho-p38 MAPK rabbit monoclonal antibody (1:1,000; Cell Signaling Technology), anti-mouse p38 MAPK rabbit monoclonal antibody (1:1,000; Cell Signaling Technology), anti-mouse Phospho-p44/42 MAPK rabbit monoclonal antibody (1:1,000; Cell Signaling Technology), anti-mouse p44/42 MAPK rabbit monoclonal antibody (1:1,000; Cell Signaling Technology), anti-mouse HO-1 rabbit polyclonal antibody (1:2,000; Stressgen, BC, Canada), anti-mouse TLR2 rat monoclonal antibody (1:200; R\&D Systems Inc., Minneapolis, MN, USA), or antimouse $\beta$-actin antibody (1:5,000; Sigma) at $4^{\circ} \mathrm{C}$ overnight, as appropriate. After washing with TBS containing $0.02 \%$ (v/v) Tween 20, membranes were incubated with horseradish peroxidase-conjugated secondary antibody $(0.01 \mu \mathrm{g} / \mathrm{ml})$ at room temperature for $1 \mathrm{~h}$ and immunoreactions were visualized using the enhanced chemiluminescence detection system (GE Healthcare Life Science, Little Chalfont, UK). Multi gauge software (Fujifilm Life Science, Tokyo, Japan) was used for the quantification of the bands and all protein levels were normalized to the $\beta$-actin levels after densitometric scanning of the membranes by LAS-4000 mini Imaging System (Fujifilm Life Science).

\section{Efficiency of Bacterial Internalization within Cultured Cells}

Bacterial internalization assay was performed by using the modified method described previously (Hashino et al., 2012). TG cells were infected with each bacterial strains at a multiplicity of infection (MOI) of either 10 or 5 by centrifugation at $150 \times g$ for $10 \mathrm{~min}$ at room temperature. To measure bacterial internalization efficiency after $30 \mathrm{~min}$ of incubation at $37^{\circ} \mathrm{C}$ in atmosphere containing $5 \% \mathrm{CO}_{2}$, the cells were washed once with RPMI 1640 medium and then replaced with new media containing gentamicin $(50 \mu \mathrm{g} / \mathrm{ml})$ to kill any remaining extracellular bacteria. After $30 \mathrm{~min}$ of incubation at $37^{\circ} \mathrm{C}$ in atmosphere containing 5\% CO2, The cells were then washed three times with PBS and lysed with cold distilled water. The serial dilution of cell lysates was spread on BHI or LB plates for measuring colonyforming unit (CFU) values (Hashino et al., 2012). Dimethyl sulfoxide (DMSO, Wako), SP600125 (Wako), SB203580 (Wako), or U0126 (Wako) were added $1 \mathrm{~h}$ before infection. SOV (Sigma) was added immediately before $L$. monocytogenes infection. These inhibitors were dissolved in 1\% DMSO (v/v). Trypan blue dye exclusion staining was used for cell viability analysis.

\section{Detection of Cytotoxicity}

Cytotoxicity was detected using the Cytotoxicity Detection KitPLUS (LDH) according to the manufacturer's instructions (Roche Applied Science, Upper Bavaria, Germany). L. monocytogenes was deposited onto TG cells at a MOI of 10 or 5 by centrifugation at $150 \times g$ for $10 \mathrm{~min}$ at room temperature. To measure cytotoxicity, the infected cells were incubated at $37^{\circ} \mathrm{C}$ in atmosphere containing $5 \% \quad \mathrm{CO}_{2}$ for $30 \mathrm{~min}$, after which the cells were incubated with RPMI 1640 medium containing gentamicin $(50 \mu \mathrm{g} / \mathrm{ml})$ for $30 \mathrm{~min}$ to remove extracellular bacteria. The cells were washed once with RPMI 1640 medium, and then incubated in RPMI 1640 medium at $37^{\circ} \mathrm{C}$ in atmosphere containing $5 \% \mathrm{CO}_{2}$ for $6 \mathrm{~h}$. SOV $(100 \mu \mathrm{M})$ was added immediately before L. monocytogenes infection.

\section{Determination of Cell Death}

Cell death was assessed using the JC-1 Mitochondrial Membrane Potential Assay Kit (Cayman Chemical, Ann Arbor, MI, USA) according to the manufacturer's instructions. Bacteria were deposited onto TG cells on coverslips by centrifugation $(150 \times g$, $10 \mathrm{~min}$, room temperature), incubated at $37^{\circ} \mathrm{C}$ in atmosphere containing 5\% $\mathrm{CO}_{2}$ for $30 \mathrm{~min}$, and then incubated in RPMI 1640 medium containing gentamicin $(50 \mu \mathrm{g} / \mathrm{ml})$ for $30 \mathrm{~min}$. The cells were washed once with RPMI 1640 medium, and then incubated in RPMI 1640 medium at $37^{\circ} \mathrm{C}$ in atmosphere containing $5 \%$ 
$\mathrm{CO}_{2}$ for $6 \mathrm{~h}$. For JC-1 staining, cells were incubated with JC-1 staining solution at $37^{\circ} \mathrm{C}$ for $15 \mathrm{~min}$. The samples were washed twice with assay buffer. Fluorescent images were obtained using a FluoView FV100 confocal laser scanning microscope (Olympus, Tokyo, Japan). SOV (100 $\mu \mathrm{M})$ was added immediately before L. monocytogenes infection. Mitochondrial membrane potential, $\Delta \Psi_{\mathrm{m}}$, is used as an indicator of cell health. In this system, healthy cells show red fluorescence, while apoptotic or unhealthy cells show green fluorescence (Tachibana et al., 2008, 2011).

\section{Small Interfering RNA (siRNA)}

Small interfering RNA (siRNA) duplexes used for silencing mouse MRC1 (target sequence: 5' CAGCATGTGTTTCAAACTGTA-3'), TLR2 (target sequence: 5'-TTGGATGTTAGTAACAACAAT-3'), and AllStars Negative Control siRNA were purchased from Qiagen (Hilden, Germany). TG cells were transiently transfected with MRC1 siRNA using Lipofectamine RNAiMAX (Invitrogen, Carlsbad, CA, USA) with or without siRNAs at a final concentration of $36 \mathrm{nM}$ and transfected with TLR2 siRNA using X-tremeGENE siRNA Transfection Reagent (Roche Applied Science) with or without siRNAs at a final concentration of $10 \mathrm{nM}$ (Hashino et al., 2012).

\section{RNA Isolation and qPCR Analysis of MRC1}

RNA isolation was done by using the same method described previously (Tachibana et al., 2011). Total RNA for real-time PCR was prepared from TG cells by using the RNA Purification Kit (Qiagen), and the purified RNA samples were kept at $30^{\circ} \mathrm{C}$ until use. RNA was quantitated by absorption at $260 \mathrm{~nm}$ using a SmartSpec 3000 spectrophotometer (Bio-Rad). One microgram of total RNA was used to synthesize cDNA using a ReverTra Ace quantitative PCR (qPCR) reverse transcriptase (RT) kit (TOYOBO). Real-time PCR was performed using Thunderbird SYBR qPCR Mix (TOYOBO). The following primer sets were purchased from TAKARA BIO (Shiga, Japan): MRC1, forward $5^{\prime}$-AGCTTCATCTTCGGGCCTTTG-3' and reverse $5^{\prime}$-GGTGACCACTCCTGCTGCTTTAG- $3^{\prime}$; and $\beta$-actin, forward $5^{\prime}$-TGACAGGATGCAGAAGGAGA- ${ }^{\prime}{ }^{\prime}$ and reverse $5^{\prime}$ GCTGGAAGGTGGACAGTGAG-3'. All data were normalized to $\beta$-actin.

\section{Murine Experiments}

Eight to 12 week-old female ICR mice were mated individually with male ICR mice. The parent mice were obtained from Kyudo Co., Ltd. (Saga, Japan). All mice were maintained under specific pathogen-free conditions in sterile cages housed in a ventilated isolator. Fluorescent lights were cycled $12 \mathrm{~h}$ on/12 h off, and ambient temperature $\left(23 \pm 1^{\circ} \mathrm{C}\right)$ and relative humidity $(40-$ $60 \%$ ) were regulated. A vaginal plug was observed at day 0.5 of gestation. The normal gestational time for these mice is 19 days.

\section{Virulence in Pregnant Mice}

Mouse virulence assay was done by using the modified method described previously (Tachibana et al., 2011). Groups of three pregnant mice were infected intravenously at 7.5 days of gestation with approximately $2 \times 10^{4}$ cells of $L$. monocytogenes strains in $0.1 \mathrm{ml}$ PBS. To check the progression of the disease, infected mice were monitored by a veterinarian every $3-4 \mathrm{~h}$ during the day phase (7:00 am to 7:00 pm). At 18.5 days of gestation, their livers and spleens were removed, weighed and homogenized in PBS. The tissue homogenates were serially diluted with PBS and plated on BHI agar plates to count the number of CFUs. Fetuses were classified as alive if there was a heartbeat and as dead if there was no heartbeat (Tachibana et al., 2011).

\section{Statistical Analyses}

Statistical analyses were performed using the ANOVA test with post hoc Tukey-Kramer test or Student's $t$-test. Statistically significant differences between groups are indicated by asterisks $\left({ }^{*} P<0.05\right)$. Values represent the means from three assays and the error bars represent standard deviations (SD).

\section{RESULTS}

\section{Dephosphorylation of MAPK Family Proteins by $L$. monocytogenes Infection of TG Cells}

Because the MAPK pathway is involved in the infection of host cells by bacterial pathogens (Krachler et al., 2011), the phosphorylation of c-Jun, p38, and ERK1/2 in TG cells after L. monocytogenes infection was analyzed by immunoblotting. Phosphorylation of c-Jun, p38, and ERK1/2 was observed in uninfected control TG cells, whereas dephosphorylation of these proteins was observed in infected TG cells (Figures 1A,B). These proteins were dephosphorylated at different times during bacterial infection. Dephosphorylation of c-Jun, p38, and ERK1/2 was observed 1-6 h, 0.5-6 h, and 0.5-6 h after infection, respectively (Figures 1A,B).

\section{Dephosphorylation of MAPK Family Proteins Induces Downregulation of HO-1}

Listeria monocytogenes internalize into host cells and induce host cell death (Disson and Lecuit, 2013). In a previous study, we suggested that HO-1 inhibits cell death caused by L. monocytogenes infection (Tachibana et al., 2011). To investigate whether MAPK contributes to expression of HO-1 in TG cells, the effect of MAPK inhibitors on HO-1 expression in TG cells was analyzed by immunoblotting. HO-1 expression was observed in uninfected TG cells, whereas the HO-1 expression was decreased in infected TG cells (Figure 2A). HO-1 expression was decreased by the treatment of uninfected TG cells with SP600125 (JNK inhibitor) and U0126 (ERK1/2 inhibitor), but not SB203580 (p38 inhibitor; Figure 2A). DMSO may affect HO-1 expression slightly. It was difficult to analyze HO-1 expression after bacterial infection under the MAPK inhibitor treatment, because treatment of MAPK inhibitor inhibited bacterial internalization (see Figure 3). These results suggest that the MAPK pathway contributes to HO-1 expression in TG cells. 

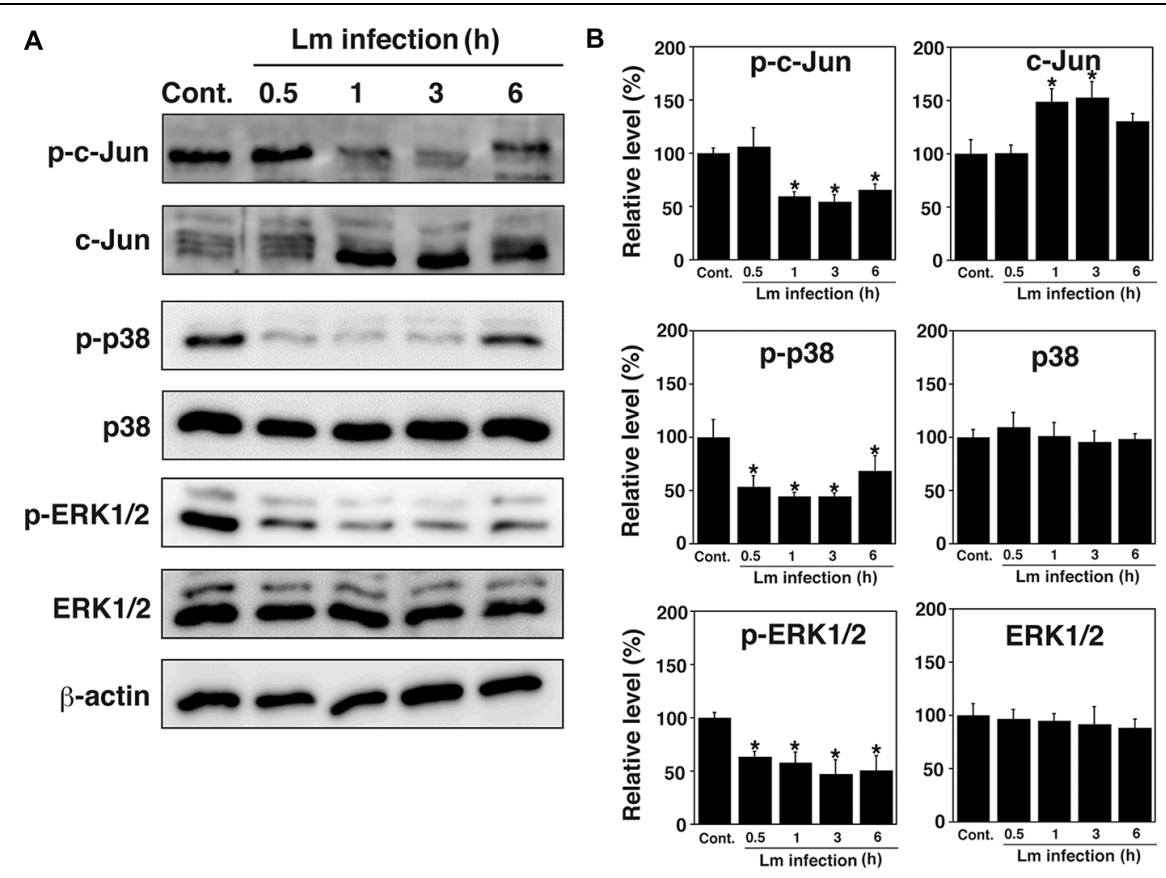

FIGURE 1 | Dephosphorylation of MAPK family proteins in trophoblast giant (TG) cells by Listeria monocytogenes infection. (A) Expression of MAPK family proteins in TG cells infected with L. monocytogenes. TG cells were infected with or without (Cont.) L. monocytogenes for the indicated number of hours. Production of the indicated proteins was detected by immunoblotting. $\beta$-actin was used as an immunoblotting control. Phosphorylated c-Jun, p38, and ERK1/2 are designated p-c-Jun, p-p38, and p-ERK1/2, respectively. (B) Relative intensity levels of p-c-Jun, c-Jun, p-p38, p-38, p-ERK, and ERK. The intensity levels of all MAPK family proteins were measured using Multi gauge software and normalized by the value of $\beta$-actin. Relative values to the intensity without infection (Cont.) were shown. All values represent the means and SD of three assays. ${ }^{*} P<0.05$ compared with Cont. by post hoc Tukey-Kramer test.

We next investigated that the effect of SOV, an inhibitor of protein tyrosine phosphatases, on HO-1 expression in infected TG cells by immunoblotting. A decrease in HO-1 expression was observed in infected but untreated TG cells. The downregulation of HO-1 expression caused by bacterial infection was inhibited by SOV treatment (Figure 2B). We also observed that dephosphorylation of MAPK family proteins was inhibited by SOV treatment (data not shown). In addition, we assessed the effect of SOV treatment on bacterial internalization into TG cells. The results showed that bacterial internalization into TG cells was significantly increased by SOV treatment (Figure 2C). SOV treatment did not affect cell viability that was confirmed by trypan blue dye exclusion staining.

To examine whether protein dephosphorylation induced by bacterial infection contributes to cell death, infection of L. monocytogenes to TG cells was done with or without SOV treatment and the rate of cytotoxicity and cell death was analyzed by measuring $\mathrm{LDH}$ release and the mitochondrial membrane potential. However, in this experimental system, cells with low mitochondrial membrane potential were detected as unhealthy cells (Figure 2F). Since SOV treatment increased bacterial internalization in TG cells (Figure 2C), we reduced the MOI to 5 from 10 when TG cells were treated with SOV to equalize the number of internalized bacteria. Therefore, MOI in SOV untreated and treated cells in Figures 2B,D,E were 10 and 5 , respectively. In this condition, the number of internalized bacterial was same as shown in Figure 2C. Treatment with SOV inhibited cell death induced by L. monocytogenes infection in TG cells, which was not observed in infected, untreated TG cells (Figures 2D,E).

\section{Inhibition of MAPK Family Proteins Impairs Bacterial Internalization into TG Cells}

Because HO-1 expression was decreased by treatment with JNK and ERK1/2 inhibitors, we next examined the effect of treatment with these inhibitors on bacterial internalization into TG cells. Internalization of $L$. monocytogenes into TG cells was decreased by treatment with SP600125 (JNK inhibitor), SB203580 (p38 inhibitor), and U0126 (ERK1/2 inhibitor) in a dose-dependent manner (Figure 3A). Moreover, uptake of $E$. coli by TG cells was inhibited by treatment with these inhibitors (Figure 3B). These results suggest that the MAPK pathway contributes to the bacterial internalization into TG cells. Inhibitor treatments did not affect cell viability that was confirmed by trypan blue dye exclusion staining.

\section{Expression of MAPK Family Proteins in TG Cells upon MRC1 and TLR2 Knockdown}

Previous studies have reported that Mannose receptor, $\mathrm{C}$ type 1 (MRC1) and Toll-like receptor 2 (TLR2) mediate bacterial 


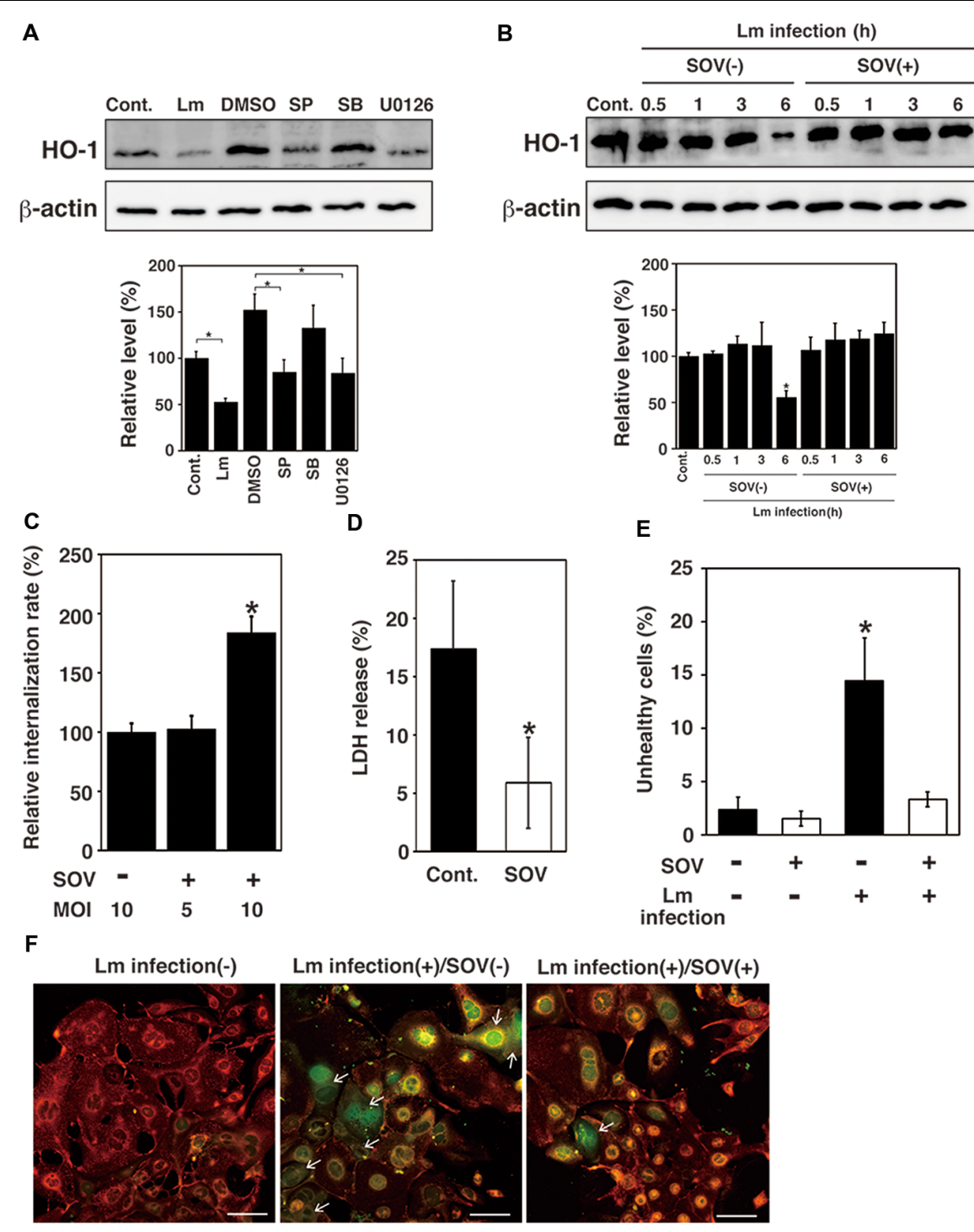

FIGURE 2 | Dephosphorylation of MAPK family proteins induces downregulation of HO-1 and TG cell death. (A) Effect of MAPK inhibitor treatment on HO-1 expression. TG cells were infected with L. monocytogenes (Lm) for $6 \mathrm{~h}$, treated with or without (Cont.) SP600125 (SP; JNK inhibitor, $25 \mu \mathrm{M}$ ), SB203580 (SB; p38 inhibitor, $25 \mu \mathrm{M}$ ), U0126 (ERK1/2 inhibitor, $25 \mu \mathrm{M}$ ), or DMSO $1 \mathrm{~h}$ before infection, respectively. Expression of HO-1 was detected by immunoblotting. $\beta$-actin was used as an immunoblotting control. (B) Effect of SOV treatment on HO-1 expression. TG cells were infected with or without (Cont.) L. monocytogenes in the presence $(\mathrm{SOV}+)$ or absence (SOV-) of SOV $(100 \mu \mathrm{M})$ for the indicated number of hours. HO-1 expression was detected by immunoblotting. $\beta$-actin was used as an immunoblotting control. (A,B) The intensity levels of HO-1 expression were measured using Multi gauge software and normalized by the value of $\beta$-actin. Relative values to the intensity without infection (Cont.) were shown. All values represent the means and SD of three assays. ${ }^{*} P<0.05$ compared with Cont. by post hoc Tukey-Kramer test. (C) Relative bacterial internalization rate. TG cells were infected with L. monocytogenes in the presence (SOV+) or absence (SOV-) of SOV $(100 \mu \mathrm{M})$, for $30 \mathrm{~min}$ at an multiplicity of infection (MOI) of 10 or 5 . All values represent the means and SD of triplicate samples from three assays. $* P<0.05$ compared with bacterial internalization in TG cells lacking SOV by post hoc Tukey-Kramer test. (D) Detection of cytotoxicity by LDH release. TG cells were infected with L. monocytogenes in the presence (SOV) or absence (Cont.) of SOV (100 $\mu$ M) at an MOI of 10 (SOV-) or 5 (SOV+). The amount of LDH released was measured after $6 \mathrm{~h}$ of infection. All values represent the means and SD of triplicate samples from three assays. ${ }^{*} P<0.05$ compared with Cont. by Student's $t$-test.

(E) Detection of cell death. TG cells were infected with L. monocytogenes in the presence (SOV+) or absence (SOV-) of SOV (100 $\mu \mathrm{M})$ for 30 min at an MOI of 10 (SOV-) or 5 (SOV+). Cell death was determined using the JC-1 Mitochondrial Membrane Potential Assay Kit after 6 h of infection. The total number of live or dead cells was determined by examination of 100 TG cells per coverslip. All values represent the means and SD of three assays. ${ }^{*} P<0.05$ compared with control by post hoc Tukey-Kramer test. (F) Fluorescence microscopic images of cell death. Red or green fluorescence indicates healthy and unhealthy cells, respectively. Arrows indicate dead cells. Bar represents $100 \mu \mathrm{m}$.

uptake by TG cells (Watanabe et al., 2010; Hashino et al., 2012). We hypothesized that activation or expression of MAPK family proteins may be mediated by MRC1 and TLR2. To examine whether MRC1 and TLR2 contribute to the activation or expression of MAPK family proteins, the phosphorylation and expression of c-Jun, p38, and ERK1/2 in TG cells were 


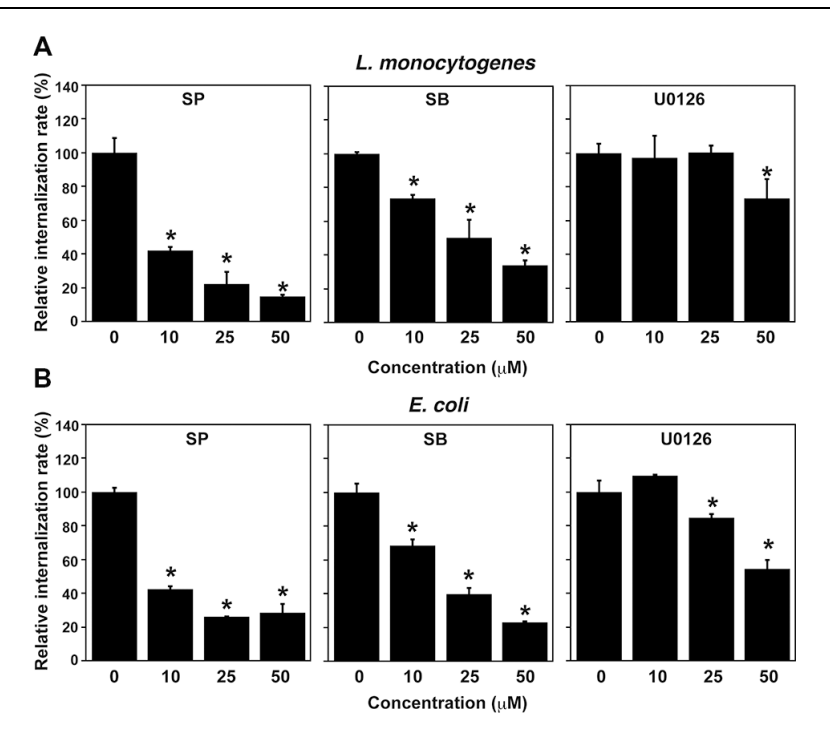

FIGURE 3 | Treatment with MAPK inhibitors inhibits $L$. monocytogenes infection in TG cells. (A) Effect of MAPK inhibitor treatment on

L. monocytogenes infection. TG cells were treated with SP600125 (SP; JNK inhibitor), SB203580 (SB; p38 inhibitor), or U0126 (ERK1/2 inhibitor) at the indicated concentration for $1 \mathrm{~h}$ and then infected with $L$. monocytogenes for 30 min at an MOI of 10. (B) Effect of MAPK inhibitor treatment on uptake of Escherichia coli. TG cells were treated with MAPK inhibitors as described above and then infected with E. coli for $30 \mathrm{~min}$ at an $\mathrm{MOI}$ of 10 . (A,B) All values represent the means and SD of triplicate samples from three identical experiments. ${ }^{*} P<0.05$ compared with bacterial internalization in TG cells without treatment by post hoc Tukey-Kramer test.

analyzed by immunoblotting after the knockdown of these receptors. The amounts of endogenous MRC1 and TLR2 were reduced by transfecting TG cells with MRC1- or TLR2-specific siRNA duplexes. MRC1 expression was significantly reduced and TLR2 expression was no longer detectable $48 \mathrm{~h}$ after transfection of TG cells with MRC1- or TLR2-specific siRNA, however, transfection with control siRNA had no effect on expression (Figures 4A,B). Because MRC1 is difficult to detect by immunoblotting, MRC1 expression was analyzed by reverse transcription quantitative PCR. Although MRC1 knockdown did not affect the phosphorylation or expression of c-Jun, p38, or ERK1/2 in TG cells (Figures 4C,E,G), TLR2 knockdown reduced the expression of c-Jun, p38, and ERK1/2 (Figures 4D,F,H). These results suggest that TLR2 plays critical roles in signal transduction through the MAPK pathway in TG cells.

\section{Infection-associated Abortion and Dephosphorylation of MAPK Family Proteins Depends on LLO}

The thiol-activated, cholesterol-dependent, pore-forming toxin LLO is a major virulence factor of L. monocytogenes (HernándezFlores and Vivanco-Cid, 2015). To investigate whether LLO contributes to the dephosphorylation of MAPK family proteins, TG cells were infected with wild-type L. monocytogenes EGD, an LLO deletion mutant $(\Delta h l y)$, and an LLO-complemented strain $(\Delta h l y:: h l y)$. Subsequently, the phosphorylation of c-Jun, p38, and ERK1/2 in these cells was analyzed by immunoblotting. Phosphorylation of c-Jun, p38, and ERK1/2 was observed in uninfected TG cells and in TG cells infected with LLO deletion mutant. Dephosphorylation of these proteins was observed in TG cells infected with wild-type EGD and with LLO-complemented strain (Figure 5A).

To investigate whether LLO contributes to the expression of HO- 1 in TG cells, TG cells were infected with the three strains described above, and HO-1 expression in these cells was analyzed by immunoblotting. HO-1 expression was observed in uninfected TG cells and in TG cells infected with the LLO deletion mutant. HO-1 expression was decreased in TG cells infected with wildtype EGD and with the LLO-complemented strain infection (Figure 5B).

Further, we investigated the role of LLO in infectionassociated abortion induced by L. monocytogenes. In order to construct a mouse model of infection-associated abortion induced by L. monocytogenes, the numbers of fetuses aborted by infected mice were counted on day 18.5 of gestation. All fetuses were aborted when the mice were infected with wild-type L. monocytogenes on day 7.5 of gestation. Almost fetuses were still alive when the mice were infected on days 10.5 and 11.5 of gestation. No abortion was observed when the mice were infected on day 14.5 of gestation. Therefore, we analyzed abortion caused by L. monocytogenes infection on day 7.5 of gestation. Infectionassociated abortion was observed in pregnant mice infected with wild-type EGD and the LLO-complemented strain, whereas the LLO deletion mutant did not induce infection-associated abortion (Figure 6A). We next examined bacterial colonization of the spleen and liver. Replicating bacteria were observed in both the spleen and liver of mice infected with wild-type EGD and the LLO-complemented strain, whereas replicating bacteria were undetectable in the spleen and liver of mice infected with the LLO deletion mutant (Figures 6B,C). Infection with wild-type EGD and the LLO-complemented strain significantly increased the weight of the spleen (Figure 6D), while bacterial infection had no significant effect on the weight of the liver (Figure 6E).

\section{DISCUSSION}

MAPK activation induces the expression of multiple genes that regulate inflammatory responses. Intracellular pathogens manipulate MAPK pathways to increase their virulence (Krachler et al., 2011; Arthur and Ley, 2013). Several bacterial pathogens, including Mycobacterium tuberculosis, activate MAPK pathways and promote invasion of host cells (Schorey and Cooper, 2003). In contrast, Yersinia sp. and Shigella sp. inhibit phosphorylation of MAPK and negatively regulate proinflammatory responses (Orth et al., 1999; Reiterer et al., 2011). In this study, dephosphorylation of c-Jun, p38, and ERK1/2 was observed during L. monocytogenes infection of TG cells. When L. monocytogenes is internalized into endothelial cells, p38 is activated and IL-8 secretion is induced in a nucleotide-binding oligomerization domain (Nod) 1-dependent manner (Opitz et al., 2006). Although MAPK plays an important role in immune responses to L. monocytogenes infection, its 
A

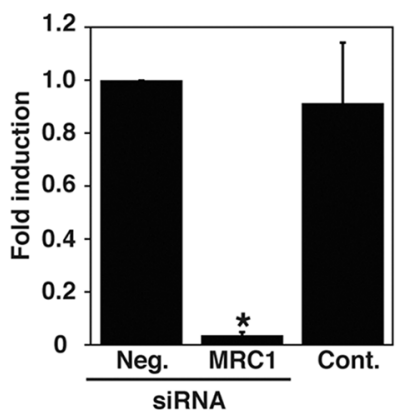

C

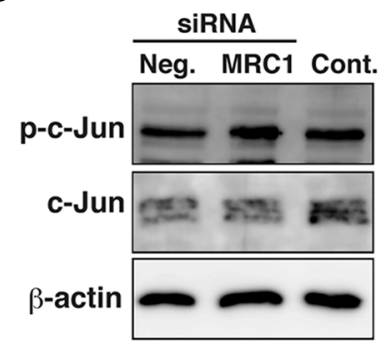

E

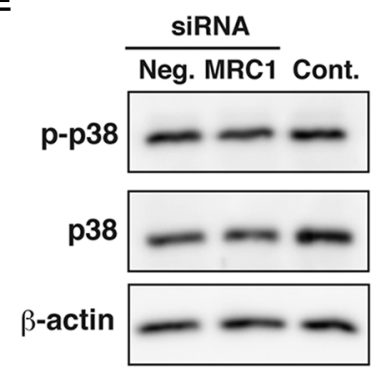

G

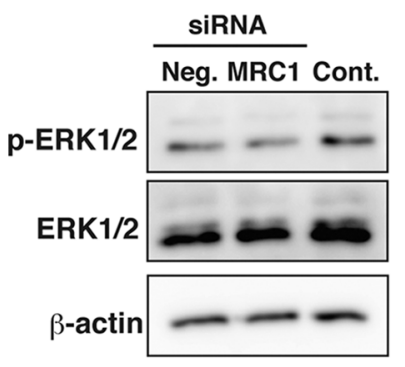

B

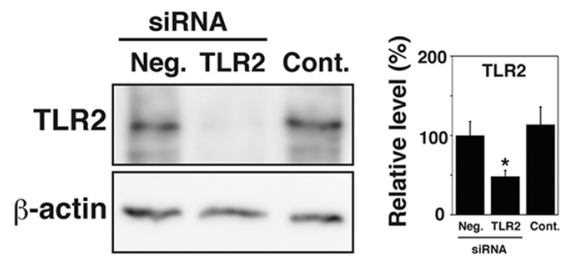

D
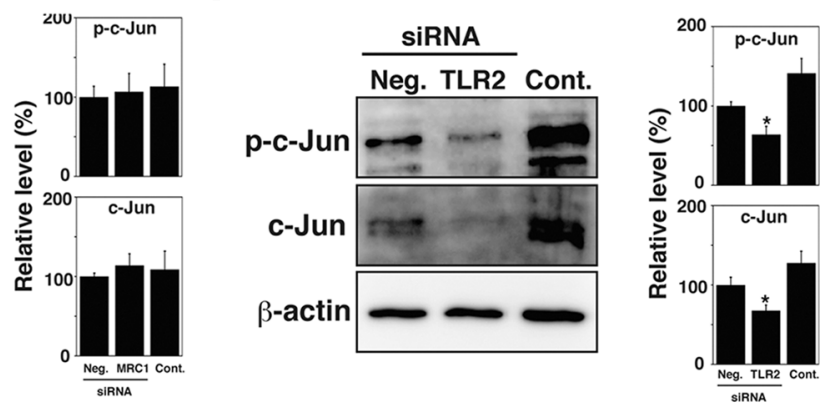

F
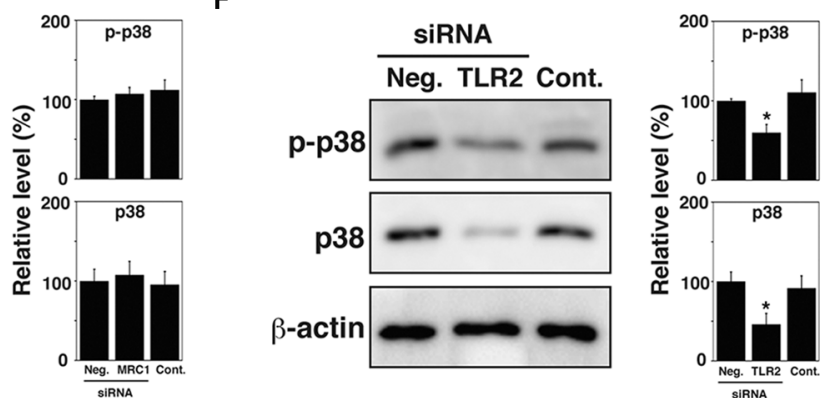

H

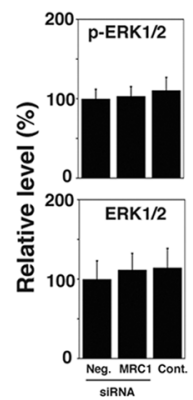

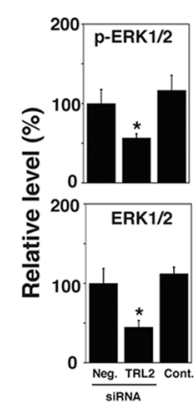

FIGURE 4 | Expression of MAPK family proteins in MRC1 and TLR2 knock-down TG cells. (A,B) Expression of MRC1 and TLR2. TG cells were treated for $48 \mathrm{~h}$ with or without (Cont.) siRNA-targeting MRC1 (A) or TLR2 (B). AllStars Negative Control siRNA (Neg.) was used for a negative control. Production of the indicated proteins was monitored by qPCR (A) or immunoblotting (B). $\beta$-actin was used as a control. (C,D) Detection of C-Jun and phosphorylated C-Jun (p-C-Jun) in MRC1 (C) or TLR2 (D) knock-down TG cells by immunoblotting. (E,F) Detection of p38 and phosphorylated p38 (p-p38) in MRC1 (E) or TLR2 (F) knock-down TG cells by immunoblotting. (G,H) Detection of ERK1/2 and phosphorylated ERK1/2 (p-ERK1/2) in MRC1 (G) or TLR2 (H) knock-downed TG cells by immunoblotting. (B-H) The intensity levels of each protein expression were measured using Multi gauge software and normalized by the value of $\beta$-actin. Relative values to the intensity of Neg. were shown. (A-H) All values represent the means and SD of three assays. ${ }^{*} P<0.05$ compared with Neg. by post hoc Tukey-Kramer test.

role in the internalization of bacteria into TG cells was unclear. YopJ, a Yersinia sp. virulence factor, is injected directly into host cells through a needle-like complex called the type III secretion system (Espinosa and Alfano, 2004). YopJ inhibits
MAPK pathways and the NF- $\mathrm{B}$ pathway by preventing the activation of MAP kinase kinase (MKK) and IкB kinase b (IKKb) and promotes host cell death (Orth et al., 1999). Since L. monocytogenes infection also induces cell death in TG cells 


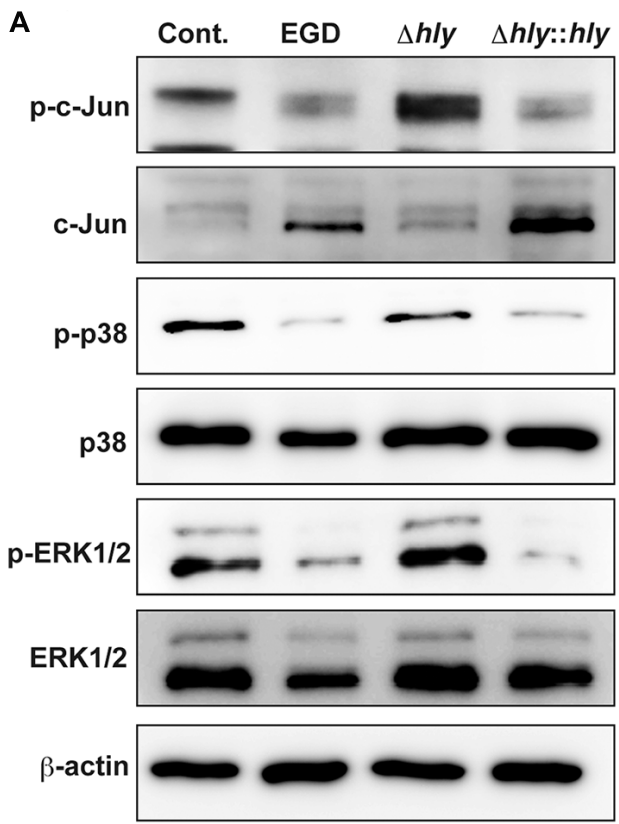

B

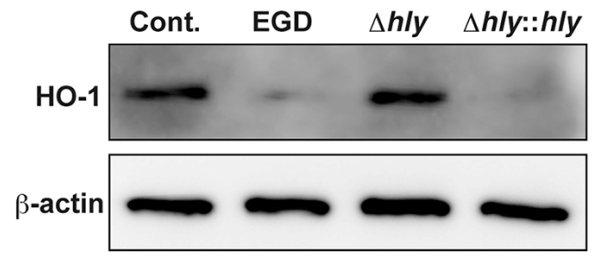

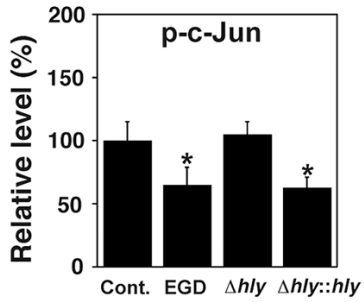
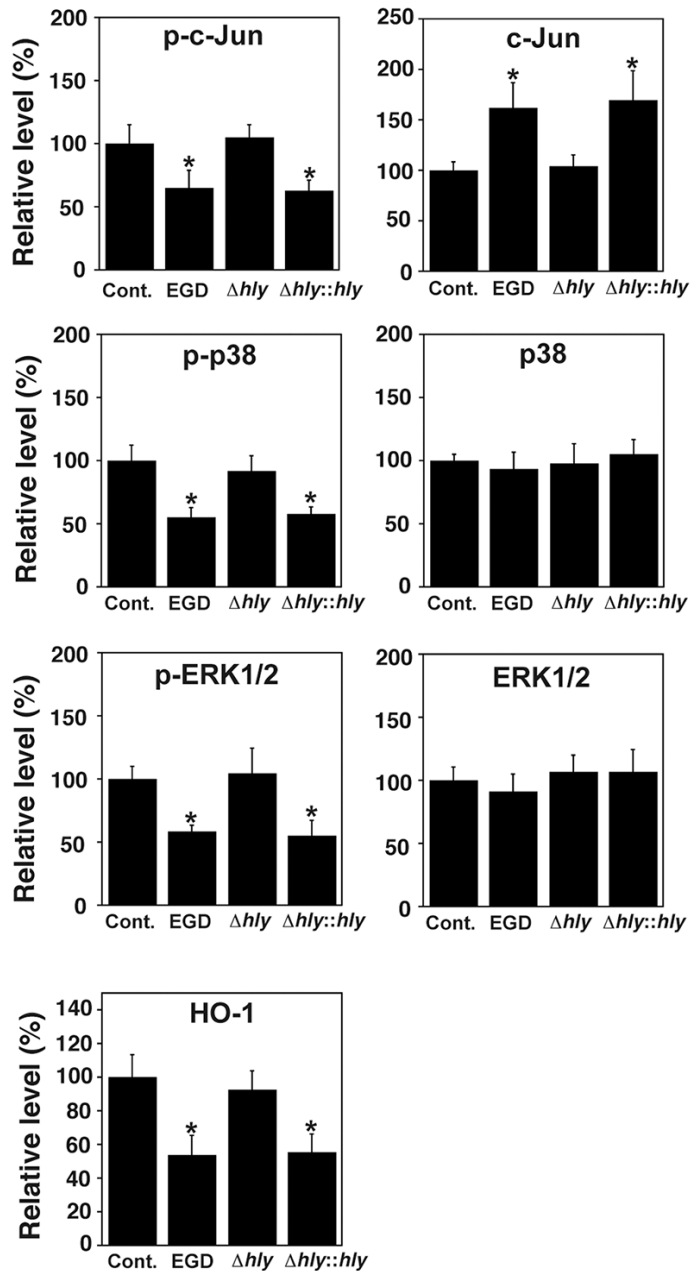

FIGURE 5 | LLO contributes to dephosphorylation of MAPK family proteins and downregulation of HO-1. (A) Expression of MAPK family proteins. TG cells were infected with or without (Cont.) L. monocytogenes wild-type strain EGD, LLO deletion mutant ( $\Delta h / y)$, or LLO-complemented strain ( $\Delta h / y:$ : $h l y)$ for $3 \mathrm{~h}$.

Expression of the indicated proteins was detected by immunoblotting. $\beta$-actin was used as an immunoblotting control. Phosphorylated c-Jun, p38, and ERK1/2 are indicated as p-c-Jun, p-p38, and p-ERK1/2, respectively. (B) Expression of HO-1. TG cells were infected with the L. monocytogenes strains described above for $6 \mathrm{~h}$. Expression of $\mathrm{HO}-1$ was detected by immunoblotting. $\beta$-actin was used as an immunoblotting control. $(\mathbf{A}, \mathbf{B})$ The intensity levels of each protein expression were measured using Multi gauge software and normalized by the value of $\beta$-actin. Relative values to the intensity without infection (Cont.) were shown. All values represent the means and SD of three assays. ${ }^{*} P<0.05$ compared with Cont. by post hoc Tukey-Kramer test.

(Tachibana et al., 2011), dephosphorylation of c-Jun, p38, and ERK1/2 is thought to contribute to TG cell death induced by bacterial infection.

MAPK pathways are also known to be associated with the production of HO-1 (Paine et al., 2010). HO-1 plays key roles in cytoprotection, antioxidation, and anti-inflammation (Hegazi et al., 2005; Nakahira et al., 2006). During spontaneous abortion, HO-1 is downregulated at the fetal-maternal interface in both human and mice (Yachie et al., 1999). We reported previously that HO-1 contributed to abortion caused by L. monocytogenes and B. abortus infection (Tachibana et al., 2008, 2011). B. abortus is a Gram-negative, intracellular, zoonotic bacterium. These bacteria cause downregulation of $\mathrm{HO}-1$ in the placenta, resulting in abortion (Tachibana et al., 2008). In this study, we showed that inhibition of c-Jun and ERK1/2 pathway causes downregulation of HO-1. Inhibition of protein dephosphorylation by SOV treatment blocks the downregulation of HO-1 and TG cell death caused by bacterial infection. Furthermore, our results suggested that TG cells survived if downregulation of HO-1 was not induced, although a large number of bacteria were internalized into TG cells. Besides, not only down regulation of HO-1 but also bacterial infection is necessary for induction of TG cell death (Tachibana et al., 2008, 2011). Therefore, it is speculated that the death of TG cells resulting from L. monocytogenes infection may be caused by the downregulation of HO-1 due to the dephosphorylation of MAPK family proteins. Therefore, dephosphorylation of MAPK family proteins by L. monocytogenes infection may be first step to infection-associated abortion, but detail mechanism of infection-associated abortion is still unclear. 

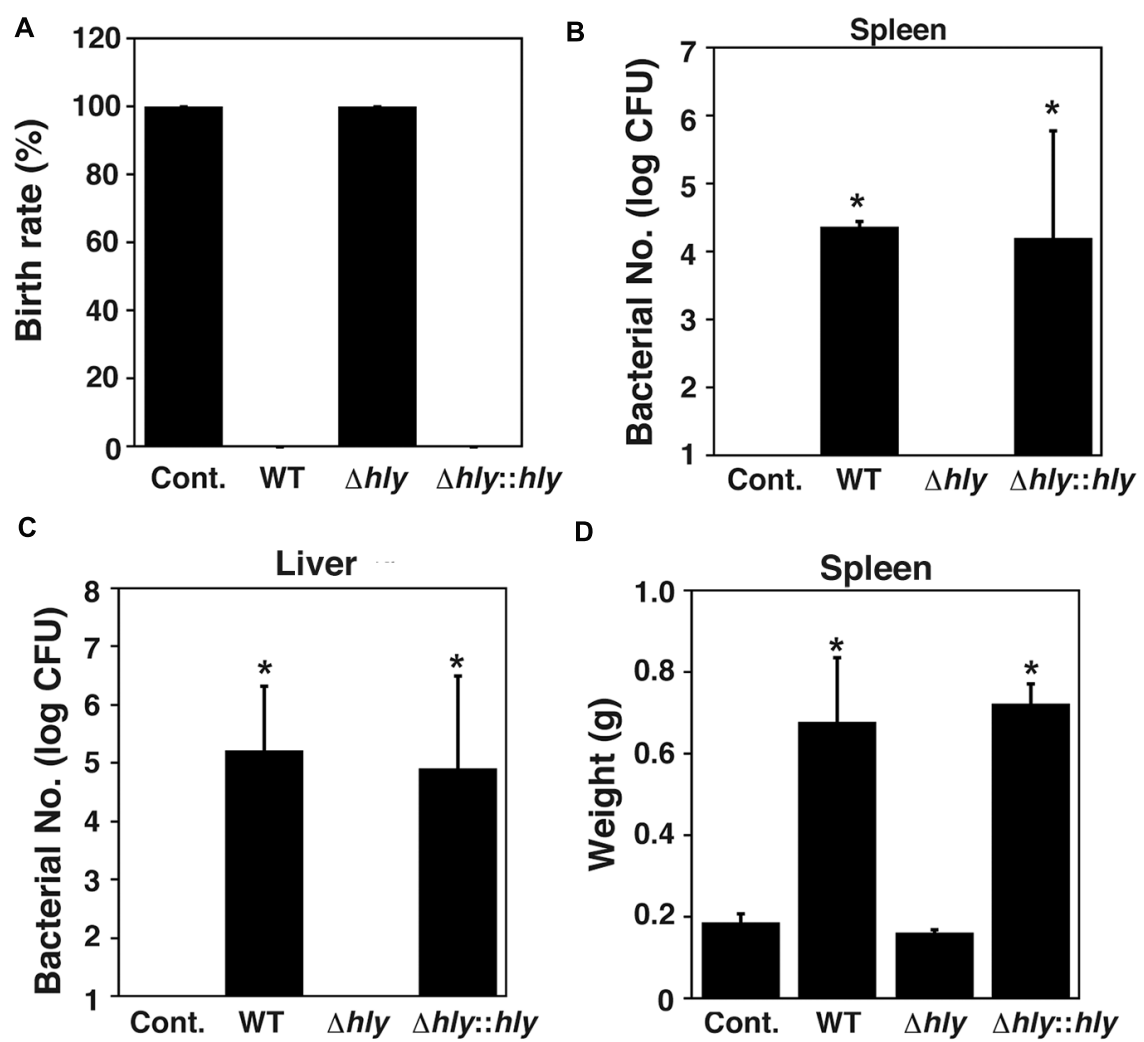

\section{D}

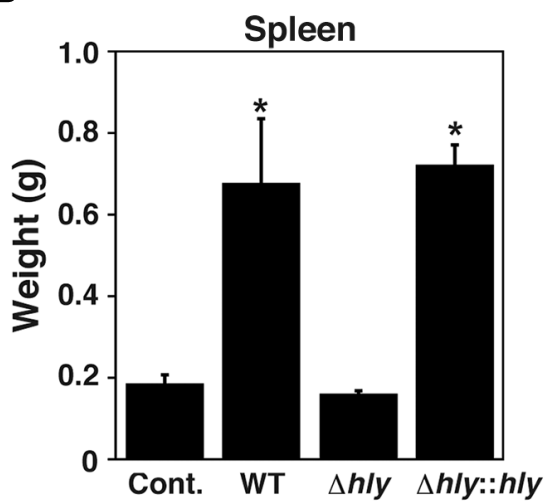

E

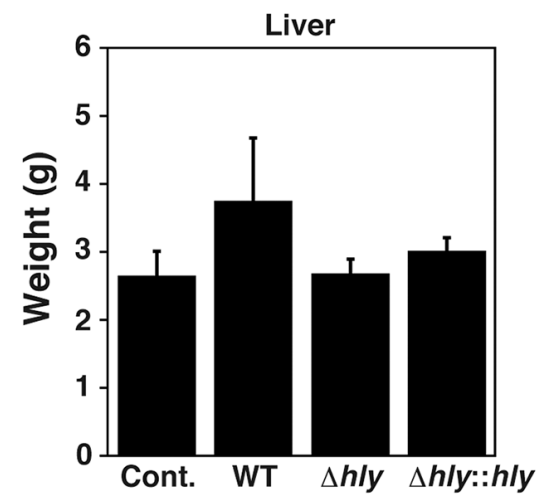

FIGURE 6 | LLO contributes to infection-associated abortion. (A) Birth rate. Groups of three pregnant animals were infected intravenously at 7.5 days of gestation with approximately $2 \times 10^{4}$ cells of L. monocytogenes wild-type strain EGD, LLO deletion mutant ( $\Delta$ hly), and LLO-complemented strain ( $\Delta$ hly::hly). (B,C) Number of bacteria in the spleen (B) and liver (C) of mice infected with the L. monocytogenes strains described above. At 18.5 days of gestation, their spleens and livers were removed and homogenized. The serially diluted tissue homogenates were plated on BHI agar plates and the number of CFU was determined. (D,E) Weights of spleen (D) and liver (E) from mice infected with the $L$. monocytogenes strains described above. (B-E) All values represent the means and SD $(n=9)$. ${ }^{*} P<0.05$ compared with Cont. by post hoc Tukey-Kramer test.

Since SOV treatment enhanced internalization of $L$. monocytogenes into TG cells, phosphorylated proteins contributed to bacterial internalization. Phosphatidylinositol 3-kinase (PI3K)/Akt pathway is activated by binding to phosphorylated proteins (Wang et al., 2015), and our previous study showed that the activation of $\mathrm{PI} 3 \mathrm{~K} / \mathrm{Akt}$ pathway contribute to L. monocytogenes infection in TG cells (Tachibana et al., 2015). In this study, we demonstrated that phosphorylation of MAPK family proteins also contributes to bacterial internalization. This data indicates that internalization of bacteria is controlled through various intracellular signaling pathway including MAPK and PI3K/Akt pathway. Although activation of the MAPK pathway is required to enhance bacterial internalization, L. monocytogenes induced dephosphorylation of MAPK family proteins in TG cells. The level of MAPK activity in TG cells is usually high, allowing TG cells to internalize macromolecules, 
such as bacteria. Therefore, the ability of TG cells to internalize additional bacteria would decrease after L. monocytogenes infection. This phenomenon is believed to prevent rapid cell death by sequential bacterial infection. This method of infection control by L. monocytogenes in TG cells may be important for intracellular bacterial growth and the induction of infectionassociated abortion.

In our previous studies, we showed that several receptors located on TG cells contribute to L. monocytogenes infection, such as MRC1, TLR2, and class B scavenger receptor type 1 (SR-B1; Watanabe et al., 2010; Hashino et al., 2012). Knockdown of these receptors inhibited the uptake of $L$. monocytogenes by TG cells. Although it is well known that signal transduction mediated by TLR2 activates the MAPK pathway (Re and Strominger, 2001), the role of MRC1 during the signal transduction remains unclear. The results of this study showed that TLR2 contributes to the expression of MAPK family proteins in TG cells, but that MRC1 was not involved. Since MAPK signaling pathway seemed to play important role in internalization of bacteria and cell death, TLR2 may be a key factor in controlling L. monocytogenes infection in TG cells.

Listeriolysin $\mathrm{O}$ is known as a major virulence factor and contributes to bacterial escape from the phagocytic vacuole in the host cell. Recent studies have revisited the role of LLO and are providing new functions of LLO (Hamon et al., 2012). Infection with L. monocytogenes causes fragmentation of the host mitochondrial network through the pore-forming action of its toxin LLO before bacterial entry (Stavru et al., 2011b). LLO has been described as highly lytic when applied to nucleated cells and can induce a wide range of cell death types. L. monocytogenes infection induces apoptosis in the cells of the spleen, lymph nodes, liver, and brain (HernándezFlores and Vivanco-Cid, 2015). The in vitro results of LLOmediated induction of apoptosis are in agreement with in vivo observations (Carrero et al., 2004). During L. monocytogenes infection of a macrophage cell line, the bacterium induces expansion of the endoplasmic reticulum (ER) and initiates a stress response to unfolded proteins (unfolded protein response or UPR). The induction of this ER stress response is dependent on the production of LLO. ER stress limits the number of intracellular bacterial, but sustained ER stress results in apoptotic cell death (Pillich et al., 2012). In this study, we showed that dephosphorylation of MAPK family proteins during L. monocytogenes infection in TG cells is dependent on LLO. A mutant lacking LLO did not induce infection-associated abortion, suggesting that the modulation of infection in the placenta should be advantageous toward L. monocytogenes infection.

\section{REFERENCES}

Amarante-Paffaro, A., Queiroz, G. S., Correa, S. T., Spira, B., and Bevilacqua, E. (2004). Phagocytosis as a potential mechanism for microbial defense of mouse placental trophoblast cells. Reproduction 128, 207-218. doi: 10.1530/rep.1.00214

Arthur, J. S., and Ley, S. C. (2013). Mitogen-activated protein kinases in innate immunity. Nat. Rev. Immunol. 13, 679-692. doi: 10.1038/nri3495

\section{CONCLUSION}

Dephosphorylation of MAPK family proteins by L. monocytogenes in TG cells contributes to TG cell death induced by bacterial infection. Thus, LLO plays an important role in both TG cell death and infection-associated abortion.

\section{AUTHOR CONTRIBUTIONS}

Conceived and designed experiments: $\mathrm{MH}, \mathrm{MW}$.

Performed the experiments: MH, MT, TN, KW, TS.

Analyzed the data: MH, MT, TN, HH, KT, MM, KW, TS, MW.

Contributed reagents/materials/analysis tools: $\mathrm{HH}, \mathrm{KT}, \mathrm{MM}$.

Wrote the paper: $\mathrm{MH}, \mathrm{MW}$.

All authors read and approved the final manuscript.

\section{FUNDING}

This work was partially supported by a Grant-in-Aid for Scientific Research (C) 22580333 to TS, MEXT TOKUBETSUKEIHI to MW from the Ministry of Education, Culture, Sports, Science and Technology (MEXT) and by a KAKENHI Grant (Number 26850181) to MT from the Japan Society for the Promotion of Science (JSPS). MH acknowledges the support from a JSPS Research Fellowship for Young Scientists (DC1).

\section{ACKNOWLEDGMENT}

We would like to thank Dr. Toshiyuki Murase (Tottori University) for helpful discussions.

\section{ETHICS STATEMENT}

This study was performed in strict accordance with recommendations in the Guidelines for Proper Conduct of Animal Experiments stipulated by the Science Council of Japan. All experimental protocols involving the use of animals were approved by the Animal Research Committee of Yamaguchi University (Permit Number: 141). Animal studies were performed in compliance with the Yamaguchi University Animal Care and Use guidelines. The mice were sacrificed by overdose of isoflurane and all efforts were made to minimize suffering by using isoflurane anesthesia.

Baczyk, D., Satkunaratnam, A., Nait-Oumesmar, B., Huppertz, B., Cross, J. C., and Kingdom, J. C. (2004). Complex patterns of GCM1 mRNA and protein in villous and extravillous trophoblast cells of the human placenta. Placenta 25, 553-559. doi: 10.1016/j.placenta.2003. 12.004

Carrero, J. A., Calderon, B., and Unanue, E. R. (2004). Listeriolysin O from Listeria monocytogenes is a lymphocyte apoptogenic molecule. J. Immunol. 172, 4866-4874. doi: 10.4049/jimmunol.172.8.4866 
Chang, L., and Karin, M. (2001). Mammalian MAP kinase signalling cascades. Nature 410, 37-40. doi: 10.1038/35065000

Chora, A. A., Fontoura, P., Cunha, A., Pais, T. F., Cardoso, S., Ho, P. P., et al. (2007). Heme oxygenase-1 and carbon monoxide suppress autoimmune neuroinflammation. J. Clin. Invest. 117, 438-447. doi: 10.1172/JCI 28844

Dhama, K., Karthik, K., Tiwari, R., Shabbir, M. Z., Barbuddhe, S., Malik, S. V., et al. (2015). Listeriosis in animals, its public health significance (food-borne zoonosis) and advances in diagnosis and control: a comprehensive review. Vet. Q. 1-25. doi: 10.1080/01652176.2015.1063023 [Epub ahead of print]

Disson, O., and Lecuit, M. (2013). In vitro and in vivo models to study human listeriosis: mind the gap. Microbes Infect. 15, 971-980. doi: 10.1016/j.micinf.2013.09.012

Drake, B. L., and Rodger, J. C. (1987). Phagocytic properties of cultured murine trophoblast. Placenta 8, 129-139. doi: 10.1016/0143-4004(87)90016-6

Espinosa, A., and Alfano, J. R. (2004). Disabling surveillance: bacterial type III secretion system effectors that suppress innate immunity. Cell. Microbiol. 6, 1027-1040. doi: 10.1111/j.1462-5822.2004.00452.x

Gluhovschi, C., Gluhovschi, G., Petrica, L., Velciov, S., and Gluhovschi, A. J. (2015). Pregnancy associated with systemic lupus erythematosus: immune tolerance in pregnancy and its deficiency in systemic lupus erythematosus-an immunological dilemma. J. Immunol. Res. 2015, 241547. doi: $10.1155 / 2015 / 241547$

Guzmán, C. A., Domann, E., Rohde, M., Bruder, D., Darji, A., Weiss, S., et al. (1996). Apoptosis of mouse dendritic cells is triggered by listeriolysin, the major virulence determinant of Listeria monocytogenes. Mol. Microbiol. 20, 119-126. doi: 10.1111/j.1365-2958.1996.tb02494.x

Hamon, M. A., Ribet, D., Stavru, F., and Cossart, P. (2012). Listeriolysin O: the Swiss army knife of Listeria. Trends Microbiol. 20, 360-368. doi 10.1016/j.tim.2012.04.006

Hara, H., Kawamura, I., Nomura, T., Tominaga, T., Tsuchiya, K., and Mitsuyama, M. (2007). Cytolysin-dependent escape of the bacterium from the phagosome is required but not sufficient for induction of the Th1 immune response against Listeria monocytogenes infection: distinct role of Listeriolysin $\mathrm{O}$ determined by cytolysin gene replacement. Infect. Immun. 75, 3791-3801. doi: 10.1128/IAI.01779-06

Hashino, M., Tachibana, M., Shimizu, T., and Watarai, M. (2012). Mannose receptor, $\mathrm{C}$ type 1 contributes to bacterial uptake by placental trophoblast giant cells. FEMS Immunol. Med. Microbiol. 66, 427-435. doi: 10.1111/1574695X.12009

Hegazi, R. A., Rao, K. N., Mayle, A., Sepulveda, A. R., Otterbein, L. E., and Plevy, S. E. (2005). Carbon monoxide ameliorates chronic murine colitis through a heme oxygenase 1-dependent pathway. J. Exp. Med. 202, 1703-1713. doi 10.1084/jem.20051047

Hernández-Flores, K. G., and Vivanco-Cid, H. (2015). Biological effects of Listeriolysin O: implications for vaccination. Biomed Res. Int. 2015, 360741. doi: $10.1155 / 2015 / 360741$

Hernandez-Milian, A., and Payeras-Cifre, A. (2014). What is new in listeriosis? Biomed Res. Int. 2014, 358051. doi: 10.1155/2014/358051

Hu, D., and Cross, J. C. (2010). Development and function of trophoblast giant cells in the rodent placenta. Int. J. Dev. Biol. 54, 341-354. doi: 10.1387/ijdb. 082768dh

Kim, S., Lee, D. S., Watanabe, K., Furuoka, H., Suzuki, H., and Watarai, M. (2005). Interferon- $\gamma$ promotes abortion due to Brucella infection in pregnant mice. BMC Microbiol. 5:22. doi: 10.1186/1471-2180-5-22

Krachler, A. M., Woolery, A. R., and Orth, K. (2011). Manipulation of kinase signaling by bacterial pathogens. J. Cell Biol. 195, 1083-1092. doi: 10.1083/jcb.201107132

Lang, C. Y., Hallack, S., Reiser, R., and Pfarrer, C. (2004). Cytoskeletal filaments and associated proteins during restricted trophoblast invasion in bovine placentomes: light and transmission electron microscopy and RT-PCR. Cell Tissue Res. 315, 339-348. doi: 10.1007/s00441-003-0842-x

Lee, T. S., and Chau, L. Y. (2002). Heme oxygenase-1 mediates the antiinflammatory effect of interleukin-10 in mice. Nat. Med. 8, 240-246. doi: $10.1038 / \mathrm{nm} 0302-240$

Merrick, J. C., Edelson, B. T., Bhardwaj, V., Swanson, P. E., and Unanue, E. R. (1997). Lymphocyte apoptosis during early phase of Listeria infection in mice. Am. J. Pathol. 151, 785-792.
Nakahira, K., Kim, H. P., Geng, X. H., Nakao, A., Wang, X., Murase, N., et al. (2006). Carbon monoxide differentially inhibits TLR signaling pathways by regulating ROS-induced trafficking of TLRs to lipid rafts. J. Exp. Med. 203, 2377-2389. doi: 10.1084/jem.20060845

Opitz, B., Püschel, A., Beermann, W., Hocke, A. C., Förster, S., Schmeck, B., et al. (2006). Listeria monocytogenes activated p38 MAPK and induced IL-8 secretion in a nucleotide-binding oligomerization domain 1-dependent manner in endothelial cells. J. Immunol. 176, 484-490. doi: 10.4049/jimmunol.17 6.1.484

Orth, K., Palmer, L. E., Bao, Z. Q., Stewart, S., Rudolph, A. E., Bliska, J. B., et al. (1999). Inhibition of the mitogen-activated protein kinase kinase superfamily by a Yersinia effector. Science 285, 1920-1923. doi: $10.1126 /$ science.285.5435.1920

Paine, A., Eiz-Vesper, B., Blasczyk, R., and Immenschuh, S. (2010). Signaling to heme oxygenase- 1 and its anti-inflammatory therapeutic potential. Biochem. Pharmacol. 80, 1895-1903. doi: 10.1016/j.bcp.2010.07.014

Pamplona, A., Ferreira, A., Balla, J., Jeney, V., Balla, G., Epiphanio, S., et al. (2007). Heme oxygenase-1 and carbon monoxide suppress the pathogenesis of experimental cerebral malaria. Nat. Med. 13, 703-710. doi: 10.1038/nm1586

Parast, M. M., Aeder, S., and Sutherland, A. E. (2001). Trophoblast giant-cell differentiation involves changes in cytoskeleton and cell motility. Dev. Biol. 230, 43-60. doi: 10.1006/dbio.2000.0102

Parmer, E. G. (2004). Immune responses to Listeria monocytogenes. Nat. Rev. Immunol. 4, 812-823. doi: 10.1038/nri1461

Pillich, H., Loose, M., Zimmer, K. P., and Chakraborty, T. (2012). Activation of the unfolded protein response by Listeria monocytogenes. Cell. Microbiol. 14, 949-964. doi: 10.1111/j.1462-5822.2012.01769.x

Poss, K. D., and Tonegawa, S. (1997a). Heme oxygenase 1 is required for mammalian iron reutilization. Proc. Natl. Acad. Sci. U.S.A. 94, 10919-10924. doi: 10.1073/pnas.94.20.10919

Poss, K. D., and Tonegawa, S. (1997b). Reduced stress defense in heme oxygenase 1-deficient cells. Proc. Natl. Acad. Sci. U.S.A. 94, 10925-10930. doi 10.1073/pnas.94.20.10925

Re, F., and Strominger, J. L. (2001). Toll-like receptor 2 (TLR2) and TLR4 differentially activate human dendritic cells. J. Biol. Chem. 276, 37692-37699. doi: 10.1074/jbc.M105927200

Reiterer, V., Grossniklaus, L., Tschon, T., Kasper, C. A., Sorg, I., and Arrieumerlou, C. (2011). Shigella flexneri type III secreted effector OspF reveals new crosstalks of proinflammatory signaling pathways during bacterial infection. Cell. Signal. 23, 1188-1196. doi: 10.1016/j.cellsig.2011.03.006

Ribet, D., and Cossart, P. (2015). How bacterial pathogens colonize their hosts and invade deeper tissues. Microbes Infect. 17, 173-183. doi: 10.1016/j.micinf.2015.01.004

Robbins, J. R., Skrzypczynska, K. M., Zeldovich, V. B., Kapidzic, M., and Bakardjiev, A. I. (2010). Placental syncytiotrophoblast constitutes a major barrier to vertical transmission of Listeria monocytogenes. PLoS Pathog. 6:e1000732. doi: 10.1371/journal.ppat.1000732

Robbins, J. R., Zeldovich, V. B., Poukchanski, A., Boothroyd, J. C., and Bakardjiev, A. I (2012). Tissue barriers of the human placenta to infection with Toxoplasma gondii. Infect. Immun. 80, 418-428. doi: 10.1128/IAI.05899-11

Rogers, H. W., Callery, M. P., Deck, B., and Unanue, E. R. (1996). Listeria monocytogenes induces apoptosis of infected hepatocytes. J. Immunol. 156, 679-684.

Schorey, J. S., and Cooper, A. M. (2003). Macrophage signalling upon mycobacterial infection: the MAP kinases lead the way. Cell. Microbiol. 5, 133-142. doi: $10.1046 / j .1462-5822.2003 .00263 . x$

Stavru, F., Archambaud, C., and Cossart, P. (2011a). Cell biology and immunology of Listeria monocytogenes infections: novel insights. Immunol. Rev. 240, 160-184. doi: 10.1111/j.1600-065X.2010.00993.x

Stavru, F., Bouillaud, F., Sartori, A., Ricquier, D., and Cossart, P. (2011b). Listeria monocytogenes transiently alters mitochondrial dynamics during infection. Proc. Natl. Acad. Sci. U.S.A. 108, 3612-3617. doi: 10.1073/pnas.1100126108

Tachibana, M., Hashino, M., Nishida, T., Shimizu, T., and Watarai, M. (2011). Protective role of heme oxygenase-1 in Listeria monocytogenes-induced abortion. PLoS ONE 6:e25046. doi: 10.1371/journal.pone.0025046

Tachibana, M., Hashino, M., Watanabe, K., Shimizu, T., and Watarai, M. (2015). Interferon $\gamma$-induced GTPase promotes invasion of Listeria monocytogenes into trophoblast giant cells. Sci. Rep. 5, 8195. doi: 10.1038/srep08195 
Tachibana, M., Watanabe, K., Yamasaki, Y., Suzuki, H., and Watarai, M. (2008). Expression of heme oxygenase-1 is associated with abortion caused by Brucella abortus infection in pregnant mice. Microb. Pathog. 45, 105-109. doi: 10.1016/j.micpath.2008.04.002

Tanaka, S., Kunath, T., Hadjantonakis, A. K., Nagy, A., and Rossant, J. (1998). Promotion of trophoblast stem cell proliferation by FGF4. Science 282, 2072-2075. doi: 10.1126/science.282.5396.2072

Tanoue, T., and Nishida, E. (2003). Molecular recognitions in the MAP kinase cascades. Cell. Signal. 15, 455-462. doi: 10.1016/S0898-6568(02)00112-2

Turjanski, A. G., Vaqué, J. P., and Gutkind, J. S. (2007). MAP kinases and the control of nuclear events. Oncogene 26, 3240-3253. doi: 10.1038/sj.onc.12 10415

Wang, W., Xu, S., Yin, M., and Jin, Z. G. (2015). Essential roles of Gabl tyrosine phosphorylation in growth factor-mediated signaling and angiogenesis. Int. J. Cardiol. 181, 180-184. doi: 10.1016/j.ijcard.2014. 10.148

Watanabe, K., Shin, E. K., Hashino, M., Tachibana, M., and Watarai, M. (2010). Toll-like receptor 2 and class B scavenger receptor type I are required for bacterial uptake by trophoblast giant cells. Mol. Immunol. 47, 1989-1996. doi: 10.1016/j.molimm.2010.04.013
Welsh, A. O., and Enders, A. C. (1987). Trophoblast-decidual cell interactions and establishment of maternal blood circulation in the parietal yolk sac placenta of the rat. Anat. Rec. 217, 203-219. doi: 10.1002/ar.10921 70213

Yachie, A., Niida, Y., Wada, T., Igarashi, N., Kaneda, H., Toma, T., et al. (1999). Oxidative stress causes enhanced endothelial cell injury in human heme oxygenase-1 deficiency. J. Clin. Invest. 103, 129-135. doi: 10.1172/ JCI4165

Conflict of Interest Statement: The authors declare that the research was conducted in the absence of any commercial or financial relationships that could be construed as a potential conflict of interest.

Copyright (c) 2015 Hashino, Tachibana, Nishida, Hara, Tsuchiya, Mitsuyama, Watanabe, Shimizu and Watarai. This is an open-access article distributed under the terms of the Creative Commons Attribution License (CC BY). The use, distribution or reproduction in other forums is permitted, provided the original author(s) or licensor are credited and that the original publication in this journal is cited, in accordance with accepted academic practice. No use, distribution or reproduction is permitted which does not comply with these terms. 